unmarked. The dense connective tissue in the center of the tumor was traversed by innumerable blood vessels of various sizes, running in all directions. Numerous leukocytes, lymphocytes, and plasma cells were observed along the courses of the capillaries and scattered about in the stroma. Only a few groups of cocci were found, and these were located near the base of the growth.

CASE 2.-In a man, aged 25, a law student, referred to me by Dr. Jabez N. Jackson, the lesion had developed from a tiny razor cut, on the left side of the lower lip, and had been present four months. It had been removed twice during this

\section{HYDROSALPINX WITH TWISTED PEDICLE}

\section{H. J. WHITACRE, B.S., M.D.}

TACOMA, WASH.

I believe that hydrosalpinx with twisted pedicle has not been given the attention as a definite surgical condition which is its due. Ovarian cyst with twisted pedicle receives definite consideration in every differential diagnosis in which an acute pelvic lesion with

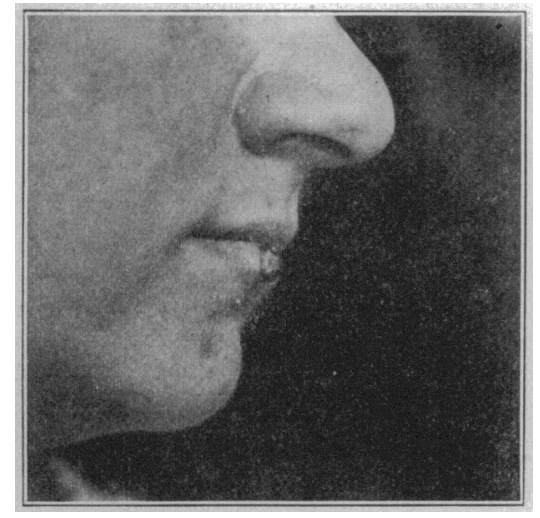

Fig. 2 (Case 1).-Granuloma pyogenicum of the lip, of eight month' duration.

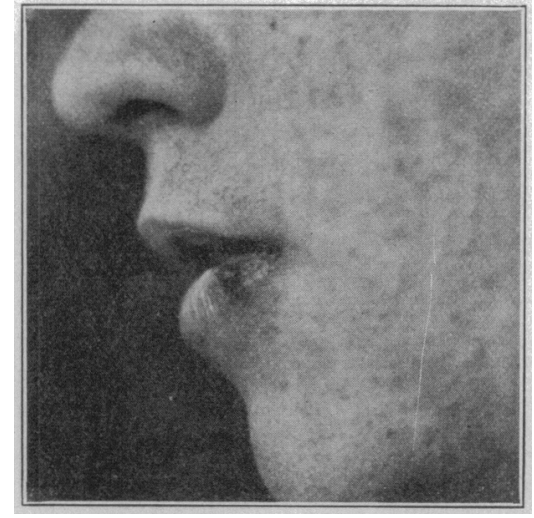

Fig. 3 (Case 2).--Granuloma pyogenicum of the lip, of five months' duration.

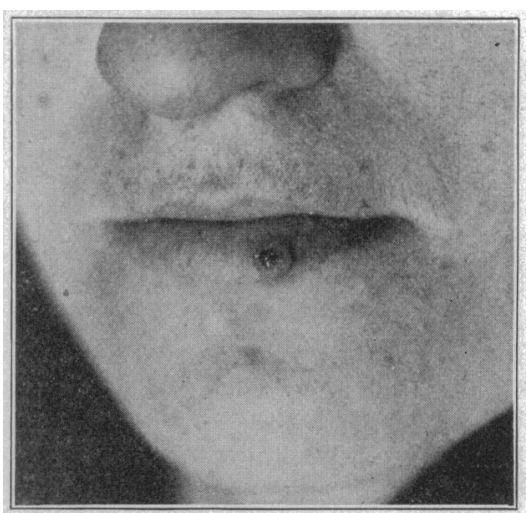

Fig. 4 (Case 3).-Granuloma pyogenicum of the lip, of seven months' duration. period, once by means of a ligature and again with scissors, but had promptly recurred each time. As in Case 1, there was profuse hemorrhage on even slight manipulation of the tumor, and the patient was greatly worried, suspecting malignancy.

CASE 3.-This occurred in a housewife, aged 30, referred to me by Dr. W. Connelly Anderson of Kansas City, Mo. The lesion which was a trifle larger than the head of an ordinary pin, had developed on the site of a fever blister, and had been present seven months. Superficial cauterization with silver nitrate had aggravated the condition instead of benefiting it. The tumor was soft and compressible, but bled on very slight provocation. The patient said that the growth temporarily increased in size immediately preceding each menstrual period.

\section{TREATMENT}

In all three instances excision, under novocain anesthesia, was practiced, the raw bases sponged dry, and then thoroughly and deeply frozen by means of a hard, pointed stick of Pusey's carbon dioxid snow. While this agent is not a direct antiseptic, it is probable that the arterial hyperemia which follows its use is of assistance in combating infection, and the cauterizing action of the refrigerant leaves little to be desired in the treatment of growths of this character.

726 Lathrop Building.

The Art of Authorship.-The two most engaging powers of an author are to make new things familiar, and familiar things new.-Johnson. tumor arises, yet hydrosalpinx with twisted pedicle is not mentioned in some of our textbooks of differential diagnosis, and others merely mention the possibility. I have encountered two such cases within a brief space of time, and feel that they should be reported. Both of these patients suffered the sudden, severe seizure which is characteristic of the same accident with ovarian cyst, and in each instance a complete twist of the broad ligament was found beneath a tremendously dilated fallopian tube. The tumor mass was in each instance from blue to black, and the fallopian tube contained blood. The lesion found in each was a hematosalpinx, and should be so styled; yet the foregoing caption is given since a study of the history of these cases, together with a careful study of the pathologic material, leaves little doubt as to the fact that these patients suffered primarily from hydrosalpinx of very considerable size; that the enlarged tube became twisted on its broad ligament pedicle in a manner quite analogous to the ovarian cyst twist, and that the effusion of blood into the tube was secondary and was the direct result of the circulatory disturbance caused by the twist in the broad ligament.

These cases recall to my mind a number of earlier cases in which a large, freely movable hydrosalpinx was encountered, and in which this twist might easily have occurred. The infrequency of the accident here- 
with reported will probably be explained by the fact that hydrosalpinx is usually accompanied by more or less extensive adhesions within the pelvis, and that these adhesions prevent free mobility of the cystlike tube.

CASE 1.-Miss A., aged 23, was referred to me in April, 1915 , by Dr. Rich of Roy, Wash. She had suffered from gonorrhea two years previously, had borne a child one year previously, and had suffered to a moderate degree from pelvic discomfort and pain. Three days previous to her atmission to the hospital, she had been seized with sudden ervere pain in the right iliac region, vomited and felt very ill. A rapidly increasing pulse and temperature, rigidity of the right rectus, constant pain, and the discovery of a tumor mass in the right side led to the conclusion that the patient suffered from acute appendicitis with abscess formation. $\mathrm{My}$ own examination of the patient introduced an element of loubt regarding this diagnosis, since bimanual examination revealed a large. rounded, movable mass which occupied the entire right half of the pelvis and extended beyond the median line. The mass was not extremely scnsitive, seemed just beneath the abdominal wall, and was not particularly marked in the culdesac. Ovarian cyst with twisted pedicle and ectopic pregnancy were not fully excluded, and an exploratory incision was made in the midline. There was much free blood-colored serum in the free peritoneal cavity, and a dark blue or black cystlike tumor presented. A complete turn was demonstrable in the pedicle of this freely movable tumor, and it became at once evident that the tumor mass was made up of a tremendously enlarged left tube and a buge ovary, and that the twisted pedicle was the broad ligament. The tumor mass, which is shown in the accompanying illustration, measured 7 inches in length and 5 inches in diameter. The recovery of the patient was uncventful.

CAsE 2.-Mrs. B., aged 45, married, multipara, was seen in consultation with Dr. P. B. Swearingen of Tacoma. It is unnecessary to give the history of this patient in detail except to state that the early symptoms of severe abdominal pain, vomiting, distention, and the failure to move the bowels hy enemas, were suggestive of intestinal obstruction, and that our subsequent study of the case led us to operate on her for ovarian cyst with twisted pedicle. The lesion was precisely the same as that found in Case 1 except that the bluish-black mass was not quite so large. This patient also made an uneventful recovery.

I feel that even though these cases present a symptomatology and call for an operative management which differs in no way from ovarian cyst with twisted pedicle, they should have a definite pathologic classification.

The Reporting of Venereal Diseases.-A recent Bulletin of the health department of New York City reviews the situation with reference to the reporting of venereal diseases, and states that there has been a perceptible falling off in the number of cases reported during 1915. It is believed that this is largely due to a falling off in the number of cases reported by hospitals and institutions. Whereas during 1914 a total of 14.484 were reported from this source, during the year 1915 the figure dropped to 10,065 , a decrease of more than 4,000 cases. The percentage of positive cases reported through the department's laboratory during 1915 also shows a diminution of 5 per cent. over that of 1914. The records show that the number of cases referred by the profession to the venereal diagnostic clinics is steadily increasing despite the larger number of physicians who are making the tests themselves. It seems that as in the past physicians have refrained from reporting their cases in private practice; only 103 cases of venereal disease having been reported through this source for the entire year of 1915. The report points out, in this connection, that every safeguard is provided to protect the secrecy of such reports, and that it is not obligatory to report the cases by name, the initials alone heing sufficient.

\section{THE MICROSCOPIC EXAMINATION OF FINGER NAIL DEPOSITS}

SIGNIFICANCE IN FORENSIC MEDICINE AND IN PUBLIC AND PERSONAL IFYGIENE

\section{ALBERT SCHNEIDER, Ph.D., M.D. SAN FRANCISCO}

The microscopic examination of the deposits under the finger nails promises to be of importance in forensic medicine and also in certain phases of public sanitation and personal hygiene. This form of examination has been known for some time, and has been practically applied in a number of criminal cases both in this country and in Europe, but so far it has not been adopted as an officially recognized routine in the examination of criminals or those suspected or accused of having committed certain crimes. The possibilities of this procedure became apparent to me over twentyfive years ago when incidentally examining the scrapings from my own finger nails and those of my laboratory assistants. The number and variety of substances found was astonishing. Since that time the microscopic cxamination of finger nail deposits has been made a laboratory exercise for students in connection with the study of fiber and of body cells and bacteria.

This particular exercise was at first sandwiched in as a diversion rather than a part of the regular course. Each student of a class of forty or fifty was requested to mount the scrapings from the nails of the second and third fingers of the right hand (in case of right handed persons) on a slide in a drop of water and to cxamine this carefully under the high power ( 450 dianeters) of the compound microscope. The findings prover interesting and not infrequently astonishing to the student. The most important part of this laboratory exercise was the interpretation of the findings. The findings gave evidence of the routine labors engaged in for periods of from one to eight days previous, and of personal habits, of the kind and quality of clothing worn, of business occupations, etc.

It was found that there was a very notable difference in the contents of the deposits of the nails of the right and the left hands, and also in the deposits of the nails: of fingers and thumb of the same liand. Numcroms: examinations proved that the ordinary methods of cleaning the hands by means of soap, hot water and clean towel, inclusive of the usual nail trimming and polishing, as observed by persons of clean and sanitary habits, does not materially alter the microscopic find. ings; in other words, the usual hand toilet operation. do not clean the hands and certainly do not cleanse tho inner surface of the free ends of the finger nails. Even the vigorous use of the nail brush with soan and hot water does not result in a removal of all the deposits. Of far greater influence is the habitual close trimming of the finger nails as observed by some persons. If the nails are regularly trimmed very ilose, to the point of nearly causing bleeding, very little deposit of any kind will find lorlgment. This practice is rare, however, and may be considered the exception to the rule.

The bacteriologic findings of the finger nail deposits are also very interesting. The streptococcus groul apparently predominates in most persons, rather than the staphylococcus or the colon bacillus group, as one might reasonably expect. The organisims found in the rather limited number of cases (143) examined predominate in the following order: 